\title{
THE FEDERATION OF VETERINARIANS FOR EUROPE (FVE) IS CALLING FOR A BAN ON THE USE OF WILD ANIMALS IN CIRCUSES ACROSS ALL EUROPE. ANOTHER CRUCIAL STEP FOR ANIMAL WELFARE IN ENTERTAINMENT WAITING FOR AN EVER MORE URGENT OFFICIAL BAN FROM EUROPEAN INSTITUTIONS.
}

\section{Carla Campanaro} Attorney at Law in Rome

The Federation of veterinary of Europe (FVE) is a veterinary organisations who represent 46 national veterinary organizations across 38 European countries and 4 vibrant Sections from 38 European countries, who strives to promote animal health, animal welfare and public health in all Europe and who works to influence national, European and even global institutions.

The $6^{\text {th }}$ of June 2015 the FVE has adopted a very important paper for animal welfare called 'position on the use of animals in travelling circuses' which is fundamental for the destiny of thousands of animals still used in the circus because in conclusion FVE, formally recommends 'all European and national competent authorities to prohibit the use of wild mammals in travelling circuses across Europe since there is by no means the possibility that their physiological, mental and social requirements can adequately be met'.

Indeed assuming that the paper starts from the logic point that the use of any animal species (including birds, reptiles, and domesticated species) in any entertainment, travelling or otherwise, should be submitted to scientific and ethological consideration for animal welfare, the FVE makes the related and decisive considerations about it.

In effect the FVE observes that the use of wild mammals, especially elephants, big cats (lions and tigers) in travelling circuses reflects a traditional, but outdated, view of wild animals.

We have to give particular attention to the adjective 'outdated' which is the focus of the matter, in effect behind this adjective there is hidden the eternal contrast 
between custom and practice and the evolution of animal rights ( well represented from the art $13^{\text {th }}$ of the Lisbon Treaty who protect animals as sentient being respecting concurrently cultural traditions etc.), that slowly and barely, fortunately, is prevailing.

First of all the FVE submits that these animals, in other words the animals in captivity, have the same genetic makeup as their counterparts in the wild and retain their natural instinctive behavioural drives and needs. Therefore, observes the FVE, they have the some etological needs that cannot be met within a travelling circus, especially in terms of housing and being able to express normal behaviours. Furthermore the FVE highlights that there is little or no educational, conservational, research or economic benefit derived from the use of wild mammals in travelling circuses that might justify their use'.

In addition to these revolutionary considerations about animal welfare in the circus, the FVE notices that there is another reason to disapprove the use of animals in the circus, that is to say the fact that 'the use of wild mammals in circuses can represent serious animal health and public health and safety risks because These wild mammals can cause physical injury to the public and their keepers and zoonotic disease transmission'.

Probably just for these reasons, as FVE mentions in his paper, public polls show that an overwhelming majority of the public wants a ban on wild animals performing in circuses and infact many European countries, such as Austria, Belgium, Bulgaria, Croatia, Cyprus, Estonia, Greece, Slovenia, Poland and Malta, have already prohibited the use of all (wild) animals in circuses while other countries are currently examining a prohibition as Netherlands and UK, or have severely restricted the number of species permitted in travelling circuses, as Denmark, Finland, Hungary, Portugal, Norway, Slovakia and Sweden.

Concluding, a crucial official scientific positions that must influences European and national institutions to ban definitively the use of wild animals in circuses across all Europe to protect health wild animals involved. 